\title{
RISK ANALYSIS AND APPLICATION OF MULTICRITERIA DECISION METHODS IN THE PROJECT MANAGEMENT PROCESS
}

\section{Snežana Maksimović}

Institut za ekonomiju i pravo, Beograd, Srbija

\section{Arben Lunjić}

JUOŠ „Maršal Tito“, Ulcinj, Crna Gora

\section{Milan Stamatović}

Poslovni i pravni fakultet, Univerzitet „Union - Nikola Tesla“, Beograd, Srbija

OMESTE

JEL kategorija rada: L38, O22, P43

\section{Apstrakt}

Rezimirajući svetske trendove u području upravljanja projektima, procena rizika dobija sve sve veći značaj. Upravljanje rizicima vodi kvalitetnijem odlučivanju, zasnovano na kvalitetnim $i$ ažurnim informacijama što stvara preduslove za uspešno ostvarenje postavljenih projektnih ciljeva. Savremeno poslovanje između ostalog prepoznaje i povećanje standardizacije $i$ upotrebe web tehnologija, autsorsing u upravljanju projektima, povećanje broja nestandardnih projekata, naglasak na upravljanju rizicima i na komunikaciji. Da bi se to ostvarilo, treba raspolagati sa ljudskim resursima koji imaju odgovarajuća znanja, sposobnosti i veštine za upravljanje različitim vrstama rizika, ali prvenstveno razumevanje i prepoznavanje potrebe za tim, jer i sam proces upravljanja rizicima nosi određene troškove i vremenske zahteve. Predmet istraživanja ovog rada predstavlja analizu postupaka i mera u proceni $i$ upravljanju rizicima, kao i novih alata za osiguranje kvaliteta u procesima upravljanja projektima. Ovim radom smo nastojali da dokažemo da iako nije moguće ukloniti sve rizike iz poslovanja, jer su rizici faktor poslovanja, naglasak treba staviti na upravljanje rizicima u smislu odgovora na rizik, ublažavanja mogućih nepovoljnih uticaja ili da se osigura spremnost na rizike koji se ne mogu lako kontrolisati.

Adresa autora zaduženog za korespodenciju: Snežana Maksimović 䒠"galena.mcl@gmail.com
Ključne reči: $\quad$ upravljanje rizicima, javni investicioni projekti, dobro upravljanje, modeli odlučivanja, projektni tim 


\begin{abstract}
Summarizing global trends in project management, risk assessment is gaining to be more important. Risk management leads to better decision-making, based on quality and up-to-date information, which creates the preconditions for the achievement of the set project goals. Modern business recognizes, among other things, an increase in the standardization and use of web technologies, outsourcing in project management, an increase in the number of non-standard projects, an emphasis on risk management and communication. To achieve this, it is necessary to have human resources that have the appropriate knowledge, abilities, and skills to manage different types of risks, but primarily to understand and recognize the need for them, since the risk management process itself has certain costs and time requirements. The subject of this paper is an analysis of procedures and measures in risk assessment and management, as well as new tools for quality assurance in project management processes. Through this paper, we have sought to demonstrate that while it is not possible to eliminate all business risks because risks are a business factor, the emphasis should be on the risk management in terms of risk response, mitigation of potential adverse impacts, or ensuring readiness for the risks that cannot be easy to control.
\end{abstract}

Keywords: risk management, public investment projects, good governance, decision models, the project team

\section{UVOD}

Kada govorimo o savremenim uslovima poslovanja, prisutan je trend razvoja svesti o procesu upravljanja rizicima i njihovom uticaju na celokupno poslovanje. Analize na ovu temu potvrdile su da je sistem upravljanja rizicima u svom kontinuiranom razvoju, posebno kada su u pitanju procesi upravljanja projektima. U Srbiji zakonska regulativa kojom se formalno definiše proces upravljanja rizicima je uspostavljena.

Kada je u pitanju adekvatnost upravljanja rizicima, velike kompanije koje se bave kapitalnim infrastrukturnim projektima imaju potrebu za unapređenjem formalnog procesa upravljanja rizicima. Za kapitalne infrastukturne projekte brojna istraživanja su potvrdila da bez obzira na značaj koji imaju, njihova realizacija je često neuspešna $i$ to kako $u$ pogledu neispunjenja tradicionalnih kriterijuma uspeha projekata (troškovi, vreme, kvalitet), tako i u pogledu negativih ekonomskih efekata projekata $i$ negativnih efekata projekata na društveno i ekološko okruženje.

Ova tri aspekta uticaja na okruženja projekta (ekonomski, društveni i ekološki uticaji) čine tri aspekta održivosti i primene principa održivog razvoja na konkretnom projektu. Kao glavni razlozi za odstupanja od planiranih performansi realizovanih kapitalnih infrastrukturnih projekata u literaturi se navode rizici koji proističu iz specifičnosti ovakvih projekata.

Predmet istraživanja ovog rada su faktori rizika u postizanju ciljeva projekata, primena jasno utvrđene metodologije upravljanja rizicima, procenjivanja i praćenja rizika, te preduzimanje potrebnih radnji u cilju ostvarenja željenih projektnih performansi.

Upravljanje rizicima je proces aktivnog donošenja odluka kojima se izbegavaju problemi pre nego što se pojave. Suštinsko pitanje koje se postavlja u ovom radu jeste da li uspostavljeni proces upravljanja rizicima direktno poboljšava proces donošenja odluka naročito onih koji nose velike rizike, omogućavajući menadžerima da razumeju okruženje i rizike, zaštite sebe i kompaniju i tako dostignu postavljene ciljeve.

Predviđanje događaja koji mogu da krenu naopako postaje svakodnevna aktivnost i upravljanje rizikom postaje ravnopravan proces sa ostalim procesima u poslovanju. Odgovore treba tražiti u sprovedenim analizama, ali i u tendenciji da je upravljanje rizikom u direktnoj funkciji i objektivna pretpostavka poslovnog uspeha.

\section{UPRAVLJANJE PROJEKATA}

RIZICIMA

Upravljanje rizicima projekata je celokupan proces utvrđivanja procenjivanja i praćenja rizika uzimajući u obzir postavljene ciljeve projekta. Treba da uključi procese, alate i tehnike koje će projektnim menadžerima pomoći da maksimiziraju verovatnoću nastanka i uticaja pozitivnih događaja, te da smanje mogućnost nastanka i posledice negativnih događaja. Da bi upravljanje rizikom bilo efikasno njegovo 
sprovođenje treba započeti od najranije faze planiranja projekta i kontinuirano ga sprovoditi kroz ceo životni ciklus projekta. Proaktivno upravljanje rizicima podrazumeva upravljanje rizicima od samog početka projekta, kako bi se pravovremeno identifikovali svi potencijalni rizici koji se mogu dogoditi na projektu i kako bi se sastavio plan odgovora na te rizike (Maksimović \& Stamatović, 2018, str. 4.)

Nadležnost za upravljanje projektom je odvojena od nadležnosti za redovne poslove. Obično se projekat definiše kao shema ili deo sheme angažovanja resursa, koja se analizira kao nezavisna celina. $U$ operacionim istraživanjima, projekat se definiše kao orijentisana mreža aktivnosti sa relacijom prvenstva i parametrima ( vreme, troškovi i efekti) između početnog i krajnjeg događaja.

Osnovne karakteristike projekta su njegova privremenost, jedinstvenost i postupna razrada. Svaki projekat ima svoj određeni početak i određeni kraj. Završetak projekta nastaje kada se ispune ciljevi projekta, ili kada postane jasno da se ciljevi tog projekta neće postići te se projekat ukida.

Tokom realizacije projekta, razni unutrašnji $\mathrm{i}$ spoljni faktori utiču na promene pojedinih parametara projekta, koje se ne mogu unapred sa sigurnošću predvideti. Svaki projekat ima određeni stepen nesigurnosti, odnosno postoji rizik da se predviđeni parametri neće ostvariti. Da bi se izbegli ili ublažili negativni uticaji projektom treba upravljati kroz njegov životni ciklus.

U svrhu centralnog upravljanja projektima $u$ organizacijama se formiraju sektori za upravljanje projektima, koji se fokusiraju na koordinirano planiranje i rangiranje projekata kako bi njihova realizacija bila u skladu sa poslovnim ciljevima. Sektori za upravljanje projektima imaju širok delokrug aktivnosti od edukacija, uvođenja i primene softvera, standardizovanih politika i procedura, do aktivnog upravljanja i preuzimanja odgovornosti za postizanje projektnih ciljeva. Proces osmišljavanja ovih aktivnosti predstavlja proces planiranja projekta. Sama priprema projekta se sastoji od identifikacije, preliminarne selekcije i formulacije (Vujnović, 2009).

$\mathrm{U}$ operativnom pogledu priprema se može definisati kao ona faza u planiranju projekta koja otpočinje pojavom ideje o potrebi investiranja, sledi identifikovanje mogućih i prihvatljivih investicionih rešenja, da bi se završila procenjivanjem koristi i troškova svakog od identifikovanih rešenja. Kada se uspostavi proces upravljanja rizicima i podstakne razvoj kulture upravljanja rizicima i dokumentuju najznačajniji rizici, rukovodioci projekta donose strategiju upravljanja rizicima (Službeni Glasnik Republike Srbije 99/2011).

Vrednovanje projekta se sprovodi na bazi izveštaja o izvodljivosti projekta. Na bazi sistematskog prikupljanja i vrednovanja relevantnih podataka donosi se odluka da li projekat treba preporučiti, modifikovati ili odbaciti. Vrednovanje se sastoji iz sledeća tri koraka:

a. identifikovanje količine, kvaliteta i dinamike fizičkih inputa i autputa,

b. utvrđivanje odgovarajućih cena za inpute i autpute u cilju proračuna odnosnih troškova $i$ koristi;

c. iskazivanje troškova i koristi projekta na način koji olakšava upoređivanje sa alternativnim projektima.

Vrednovanje može pokazati da je određene aspekte projekta potrebno ponovo pripremiti. Isto tako, i u fazi implementacije projekta mogu nastupiti teškoće zbog čega neke aspekte treba ponovo projektovati i vrednovati. Da bi projektni tim mogao da obradi rizike, pre svega, neophodno je njihovo prepoznavanje. Kako se uvek može naći novi rizik koji nosi neka akcija projekta, treba spoznati rizike vredne obrade i one koji se mogu zanemariti. Rizični događaj, ukoliko dođe do njega, može imati troškovne, planske ili tehničke posledice (Gates, Nicolas.\& Walker,2009, str.132.).

Zato prvi korak samog upravljanja rizicima jeste njihova procena. Osnovna podela akcija koje spadaju u procenu rizika je:

1. prepoznavanje rizika

2. analiza rizika

3. dodeljivanje prioriteta rizicima

Najvažniji zadaci u upravljanju rizikom su: konstantno procenjivanje šta može da ugrozi projekat, odlučivanje koji rizici su dovoljno važni da bi se obrađivali i implementacija strategije koja će otkloniti te rizike. Na ovaj način se izbegava neuspeh, koji uključuje prekoračenje rokova, budžeta, dobijanje neupotrebljivog rezultata ili odustajanje od projekta. 


\section{SISTEMSKI \\ PRISTUP UPRAVLJANJU RIZICIMA}

Koncept upravljanja rizicima se zasniva na osnovnoj premisi da je upravljanje rizikom planska, dugoročna, struktuirana, informativna i stalno primenljiva tehnika. Standard PMI definiše analizu rizika kao proces ispitivanja svakog pojedinačnog identifikovanog rizičnog događaja $u$ cilju procene verovatnoće njegovog nastanka i predviđanja njegovog uticaja na projekt (Kerzner, 2003). Prema ISO 17799 - The Information Security Standard (www.security-riskanalysis.com/introduction.htm), analiza rizika raščlanjena je na kvalitativnu i kvantitativnu. Kvalitativna analiza je najrašireniji pristup analizi rizika. Za kvalitativnu analizu rizika nisu potrebni podaci o verovatnoći rizičnih događaja, već se koristi procena mogućnosti gubitka (štete). Kvalitativnom analizom rizika procenjuju se prioriteti među identifikovanim rizicima za dalje aktivnosti u cilju uspešnog upravljanja rizicima. Svrha upravljanja rizikom je rano planiranje i agresivna implementacija. Dobro planiranje omogućava organizovani, sveobuhvatni i iterativni proces identifikacije i procene rizika a zatim adekvatnog reagovanja. (Stamatović, Maksimović, \& Tornjanski, 2016, str.8.).

Proces sticanja iskustva u upravljanju rizicima javnih projekata postepeno se poboljšava kroz upotrebu više različitih pilot programa i kroz razvoj strateškog i operativnog planiranja. Projekti koje opštine razvijaju, uglavnom se odnose na infrastrukturu, na regionalnom i lokalnom nivou, i smatraju se prioritetnim intervencijama za postizanje specifičnih regionalnih razvojnih ciljeva u ekonomskoj i socijalnoj koheziji ( Maksimović \& Stamatović, 2018, str.9.).

lako proces je upravljanja rizicima sada i deo zakonske regulative i ne predstavlja novinu na našim prostorima, njegovo usvajanje nije teklo bez teškoća. U ovom radu tokom istraživačkog procesa u okviru Instituta za ekonomiju i pravo iz Beogradu, sproveli smo istraživanje tokom dva ciklusa predavanja u septembru 2019 godine i februaru 2020 godine. Kroz prezentaciju programa predavanja učesnicima je najpre dat uvod u koncept upravljanja projektnim ciklusom na svim nivoima. Zatim je razmatrano pitanje definisanja političkih ciljeva koji mogu biti kvantifikovani i dati su primeri njihovog ostvarivanja. Preko dijagrama je definisan hijerarhijski odnos između programa, prioriteta, mera i aktivnosti/projekta, a zatim su predstavljeni razni elementi rizika i načini njihove identifikacije kroz programiranje procesa (projektnog) ciklusa i analizu rizika tokom celokupnog procesa planiranja projekta. Po pripremljenom inicijalnom upitniku obavljeni su razgovori, sa učesnicima predavanja (62 kancelarije za lokalni ekonomski razvoj koji se bave upravljanjem i sprovođenjem projekata na lokalnom nivou).

Ciljevi anketiranja, kao kvantitativne komponente sprovedenog istraživanja bili su dobijanje odgovora od ispitanika o uticaju najčešćih i najuticajnijih rizičnih događaja u realizaciji projekata, te njihovo mišljenje o odlučujućim faktorima za uspeh, kod pojedinačnih projekata. Prepoznavanje najuticajnijih rizičnih događaja neophodno je za modeliranje upravljanja rizicima kako bi se planiranjem odgovora na pojavu kritičnih faktora rizika, kontrolom rizika i nadzorom nad sprovođenjem odgovora na rizik, smanjio njihov negativan uticaj, odnosno povećale šanse za uspeh projekta.

Analiza rizika je metod kojim se utvrđuje koliko je željeni cilj, unapred definisan od strane učesnika, realan, i koliko su realne šanse za njegovo ostvarenje (Wideman,1999). Za svaku pretpostavku učesnicima stoje na raspolaganju dva parametra:

- Šteta naneta cilju kojem se teži, ukoliko se pretpostavka ispostavi pogrešnom;

- Verovatnoća da se pretpostavka ispostavi pogrešnom.

Pretpostavke sa „visokim uticajem“ i „visokom verovatnoćom“ zaslužuju posvećivanje vremena za razmatranje alternativa. Na pitanje kakav je uticaj imao pojedini izvor rizika (rizični događaj) na troškove projekta, ispitanici su ocenili najkritičnijim faktorom „Lošu koordinaciju svih učesnika na projektima“ za koji je aritmetička sredina ocena svih ispitanika 2,54. Prema skali 1-5 (Skala za ocenu uticaja rizičnog događaja na ciljeve projekta) ocena uticaja 2,54 označava mali do srednji uticaj na troškove projekta (rizični događaj je na povećanje troškova u odnosu na planirani iznos uticao oko 10\%). Relativna frekvencija takvog odgovora iznosi 65\%. Prema tome, može se reći da je verovatnoća pojave rizičnog događaja veoma velika, što prema skali verovatnoće pojave rizika ima „težinu“ 4. S obzirom da rizik možemo matematički izraziti kao 
umnožak verovatnoće i uticaja, proizilazi da skala prioriteta posmatranog rizičnog događaja $u$ odnosu na rizik povećanja troškova projekta iznosi 10,16 što spada u grupu „značajnih“ rizika za koje je potrebna rana obazrivost radi uspešnog odgovora na njegovu pojavu. Obzirom da su ispitanici prepoznali kao kritičan faktor uspeha lošu koordinaciju među učesnicima, možemo zaključiti da ne postoje planovi komunikacije kao deo pomoćnih planova u upravljanju projektnim ciklusom pa je u tom smislu potrebno unaprediti planski pristup upravljanju javnim projektima. Sledeći na listi je problem nedostatak kvalitetnih stručnih radnika. Isti prioritet imaju i česte izmene propisa, što još jednom potvrđuje neodrživost dosadašnjeg pristupa razvoju lokalnih zajednica.

$\mathrm{Na}$ isti način dobijena je i lista najkritičnijih izvora, odnosno faktora rizika prekoračenja rokova i rizika smanjenja kvaliteta. Na prekoračenje rokova, prema oceni ispitanika, najviše utiče „Sporost lokalnih i državnih struktura“. Zaista je u Srbiji jedan od glavnih problema sporost administracije, odnosno birokratskog aparata i to na svim nivoima, od lokalnih do organa državne uprave. „Nedostatak kvalitetnih stručnih radnika“ ispitanici smatraju glavnim faktorom rizika smanjenja kvaliteta.

Već je prethodno naglašeno da se uspešnim projektima podrazumevaju projekti čiji su:

1. troškovi manji ili jednaki planiranim,

2. vreme realizacije manje ili jednako ugovorenom,

3. kvalitet jednak ili veći od ugovorenog.

Stoga se ukupan rizik $(R u)$ može matematički prikazati kao aritmetička sredina rizika povećanja troškova $(R t)$, prekoračenja rokova $(R r)$, i smanjenja kvaliteta $(R k)$ :

$$
R u=(R t+R r+R k) / 3
$$

Osim očekivanih odgovora - kritičnih faktora uspešnosti poput sporosti lokalnih i državnih struktura, ispitanici su prepoznali kao kritičan faktor i nedostatak stručnih i kvalitetnih radnika, lošu koordinaciju među učesnicima projekta, kao i nedostatke u projektnoj dokumentaciji i nizak stepen komunikacijske integracije.

Kada su identifikovane ključne pretpostavke, za sprovođenje analize rizika, neophodno je, za svaku od njih utvrditi, raspored i verovatnoću pojavljivanja mogućih vrednosti oko najbolje vrednosti, upotrebljavane u baznom slučaju (Lutovac, Maksimović, \& Janjić, 2016, str.67.).

Nakon definisanja rasporeda vrednosti ključnih promenljivih, moguće je utvrditi raspored mogućih vrednosti NPV i IRR projekta.

Prilikom ocene dobijenog rezultata, bitan aspekt analize, je postizanje kompromisa između: opcija projekta sa visokim rizikom i visokim društvenim koristima.

Nekada unapred postoje razlozi za izbor opcije projekta sa malim rizikom. U nekim situacijama ocenjivač i predlagač projekta mogu, odstupiti od neutralizacije rizika i izabrati opciju sa manjim ili većim rizikom, da bi se ostvario očekivani profit. Takav izbor mora biti jasno obrazložen. (Gates, Nicolas,\& Walker,2009, str.137.).

Rukovođenje rizikom, uključuje specifične metode i tehnike (Kerzner,2003), za rešavanje poznatih rizika, određivanje odgovornosti za rizični problem, te procenu troškova i vreme potrebno za rešavanje rizika.

Prema PMBOK-u, planiranje odgovora na rizik je proces u kome se razvijaju opcije i određuju aktivnosti za prihvatanje rizika i reduciranje pretnji za postizanje ciljeva projekta (Project management Institute, 2006)

Mogući su eventualan odgovor na rizik - planirane aktivnosti koje će se sprovesti jedino u slučaju da do rizika stvarno dođe, te razrađene strategije za upravljanje (The Green Book,2003).

Registar rizika je nakon ove faze procesa upravljanja rizicima dopunjen podacima o prihvaćenim strategijama upravljanja rizicima, opisom aktivnosti za primenu odabrane strategije, potrebnim sredstvima i vremenom za njihovu realizaciju, nosiocima rizika (odgovorna osoba za upravljanje određenim rizikom), i njihovim odgovornostima, rezervnim planovima, rezidualnim i sekundarnim rizicima (nakon što su preduzete određene aktivnosti za odgovor na primarni rizik).

Osim registra rizika, potrebno je ažurirati plan upravljanja rizicima, te sklopiti odgovarajuće ugovore vezane za upravljanje rizicima (ugovor o osiguranju imovine i ljudi, ugovor o servisu i sl.).

\section{METODE VIŠEKRITERIJUMSKOG ODLUČIVANJA}

U upravljanju projektima, učesnici u projektu se svakodnevno susreću sa neophodnošću 
rešavanja raznovrsnih problema. Prvi deo rešavanja problema je odlučivanje, a zatim sledi primena odabrane alternative rešenja problema $i$ njeno vrednovanje.

Odlučivanje na društvenom i poslovnom nivou je uglavnom višekriterijumskog tipa, jer se mnogi faktori uzimaju u obzir, a više interesnih grupa učestvuje u procesu odlučivanja. Najčešće su ti faktori međusobno suprotstavljeni, u konfliktu su, npr. deponiju je bolje izgraditi što dalje od grada ( kriterijum blizine), ali tada je cena odvoza smeća velika (kriterijum cene koštanja usluge). Najčešće su tu suprotstavljeni i direktni interesi: niko ne želi da mu deponija smeća bude blizu! Sa druge strane svi očekuju da neko drugi plati povećanu cenu transporta i smeštaja na nenastanjene lokacije! A tamo, sa druge strane mogu da budu izvori čiste, pijaće vode, kao dragocen resurs i/ili kupališta, kao potencijalni resurs turističke privrede.

Kako pomiriti sve ove kriterijume, različite preferencije i suprotstavljene interese? Da li postoji najbolje rešenje, ili tačnije jedno najbolje rešenje? Očigledno je, međutim da svaki učesnik u odlučivanju ima svoje najbolje rešenje! Ono što je moguće u ovakvim situacijama, je da se donese najbolje kompromisno rešenje!

Da bi to bilo najbolje ( kompromisno) rešenje - i u traganju za njim, u poslednjih pet, šest decenija su razvijene metode podrške odlučivanju ovog tipa, takozvane metode višekriterijumskog odlučivanja (eng. skr. MCDA i MCDM). Za ove svrhe razvijene su brojne metode, koje su razvijane u akademskim krugovima, ali i primenjivane u praksi.

Neke od najpoznatijih metoda za podršku višekriterijumskom odlučivanju su: PROMETHEE I i II metoda, PROMETHEE DSS, ELECTRE, AHP/ANP, (metoda analitičkih hijerarhijskih procesa i slične).

\subsection{AHP Metoda}

AHP metoda (The Analytic Hierarchy Process) je jedna od najpoznatijih i najčešće upotrebljavanih metoda za višekriterijumsko odlučivanje. AHP metoda je razvijena na Wharton School of Business, sedamdesetih godina prošlog veka, a njen autor je Thomas Saaty. Primenom ove metode donosioci odluka, kompleksni problem rešavaju dekompozicijom problema, a zatim fokusiranjem na pojedine komponente (Maletič, Lasrado, Maletič \& Gomišček, 2016, str.12.). Problem se vizualizira hijerarhijskom strukturom, iz koje su vidljivi cilj, kriteriji i alternative.

Svaki kriterij i alternativa upoređuje se sa svakim srodnim faktorom na istoj hijerarhijskoj visini. Specifičnost ove metode je što se u procesu ocenjivanja pojedinih kriterija i mogućih alternativa uvažavaju i objektivni i subjektivni faktori. Osoba koja pored osnovnih podataka i informacija u procesu odlučivanja podjednako koristi, zavisno od prirode problema, sopstveno iskustvo, prethodna znanja, pa i intuiciju. Odgovarajućim matematičkim modelom sintetizira se konačan rezultat prioriteta alternativa u odnosu na postavljeni cilj.

Jedan od najčešće korišćenih programskih paketa za podršku odlučivanju koji primenjuje AHP je Expert Choice (EC). Ovim programom se može jednostavno i brzo dekomponovati problem $u$ neku od hijerarhijskih struktura. određivanje prioriteta u parovima moguće je na više načina: koristeći opisnu, numeričku ili grafičku skalu. Za svako određivanje prioriteta među elementima na određenom hijerarhijskom stupnju program automatski prikazuje postignuti stepen konzistencije.

Za osobe koje donose odluke o izboru alternativa, bitna je važnost pojedinog elementa, odnosno, kako će promena informacije o tom elementu uticati na promenu konačnog rezultata - promenu prioriteta alternativa. Ciljevi analize osetljivosti su ući u suštinu problema, odnosno pronaći jednostavan model čija će struktura omogućiti najbolje rešavanje tog problema, te proveriti ispravnost numeričkih podataka, kao i potrebu za njihovom preciznošću.

\subsection{Metod ELECTRE}

Jedna od višekriterijumskih metoda odlučivanja je i metoda ELECTRE (Karleuša, Beraković \& Ožanić, 2004, str. 15.), koja je veoma primenjiva kada treba doneti odluku u situacijama za koje važe sledeće specifičnosti:

1. Model odlučivanja sastoji se od barem tri kriterija;

2. Alternative se (za bar jedan kriterij) ocenjuju po skali rednih brojeva ili po skali malih intervala, koje nisu prikladne za upoređivanje razlika; 
3. Vrlo heterogena svojstva kriterija, što otežava ocenjivanje kriterija po jedinstvenoj skali;

4. Donosilac odluke ne prihvata svojevoljno kompenziranje gubitka po jednom od kriterija, sa dobitkom od drugog kriterija - potrebna je nekompenzacijska procedura ocenjivanja alternativa;

5. Za bar jedan kriterij vredi: male razlike u ocenjivanju nisu bitne u određivanju preferencija, dok njihov zajednički učinak može postati značajan.

Metoda ELECTRE uspešno se primenjuje u mnogim područjima. Jedan od primera primene je $\mathrm{u}$ rangiranju projekata. $U$ praksi se subjektivna ocena pri odlučivanju pokazala neprimerenom, dok se već pilotna primena ELECTRE u rešavanju ovog problema ocenila vrlo uspešnom.

Rešenje dobijeno nekom od metoda višekriterijumskog odlučivanja ne treba shvatiti kao idealno tj. najbolje (jedino) rešenje. Napred je već rečeno da je ovo kompromisno rešenje. Sama metodologija donosiocima odluke pomaže u celovitom shvatanju problema, i u skladu s tim, donošenju kvalitativnog i sprovodljivog rešenja. Ovakvim metodološkim postupkom se sprečava nepotrebno suprotstavljanje stavova javnosti, interesnih grupa i donosioca odluke, i tako postiže često nužni konsenzus.

\section{ZAKLJUČAK}

Analiza relevantnih faktora, prilikom analize rizika, ne može ukloniti i rizik, ali ga zato može svesti na prihvatljivu meru i ukloniti uslove za nastajanje velikih gubitaka. Malo je empirijskih dokaza na osnovu kojih bi se sa sigurnošću mogao definisati put koji vodi uspehu u sprovođenju projekata, ali je neophodan sistem organizovanih i svrsishodnih aktivnosti usmerenih na sve aspekte upravljanja projektnim ciklusom. Problem koji se postavlja istraživanjem ovog rada je potreba da se poveća uspešnost projektnih timova da adekvatno reaguju na relevantne događaje u okruženju. Radi se o izradi konceptualnog okvira koji treba da predstavlja „ogledalo pretenzija“, poslovne filozofije i veština projektnih menadžera u ostvarenju projektnih ciljeva.

Iz analize rizika, zaključeno je da su najkritičniji faktori rizika za javne projekte upravo: sporost lokalnih i državnih struktura, nedostatak kvalitetnih i stručnih radnika, loša koordinacija svih učesnika u projektima, nedostaci u planskoj dokumentaciji i veoma nizak nivo komunikacijske integracije.

Zaključak autora ovog rada je i da ne postoji sistemski pristup u analizi rizika u upravljanju projektnim ciklusom, takođe postoji jedna nespremnost lokalnih struktura da se prihvate transparentnih procedura, a obzirom na visok stepen političkih uticaja, preveliki je i broj tekućih pitanja. Problemi koji se takođe javljaju zbog nepostojanja sistemskog načina rada su: haos na sednicama budžeta, uključivanje slučajnih projekata $u$ investicioni aneks budžeta (često $u$ skladu sa političkim željama), sprovođenje nepripremljenih projekata, sebično ponašanje lokalnih političara, kašnjenja u realizaciji, neupućenost u mogućnosti dodatnih izvora finansiranja. Nadamo se da će stečeno iskustvo u prikupljanju informacija za ovaj rad u cilju analize najznačajnijih faktora rizika u upravljanju projektima i predlozi rešenja za primenu u konkretnim situacijama, biti od koristi projektnim menadžerima, barem kao preduslov sagledavanju i rešavanju problema u svakodnevnom poslovnom i projektnom okruženju.

\section{CITIRANA DELA}

Gates, S., Nicolas, J., \& Walker, P.L. (2009) Perceived Value of Enterprise Risk Management, University of Virginia. str.132-137.

Karleuša, B., Beraković, B., \& Ožanić (2004) Primjena ELECTRE TRI metode na izbor varijante navodnjavanja. str.15

Kerzner, H. (2003). Project Management: A Systems Approach to Planning Scheduling, and Controlling, Eighth Edition. Berea, Ohio: John Wiley \& Sons

Lutovac, M., Maksimović, S. \& Janjić, D. (2016) Procesi upravljanja projektima u javnoj upravi- Plenary and Invitation Paper, $1^{\text {rd }}$ International Conference "Economy, Law and State Administration", ELASA, str. 67 
Maksimović, S., \& Stamatović, M. (2018) "Risk management as a part of managing public investment projects", $4^{\text {th }}$ - International Scientific Conference - Innovation as an initiator of the development, Faculty of Applied Management, Economics Finance, Belgrade, str.4-9.

Maletič, D., Lasrado, F., Maletič, M., \& Gomišček, B.(2016) Analytic Hierarchy Process Application in Different Organisational Settings, str.12.

Pravilnik o zajedničkim kriterijumima za organizovanje i standardima i metodološkim uputstvima za postupanje i izveštavanje interne revizije u javnom sektoru, (2011) Službeni Glasnik Republike Srbije 99/2011

Project Management Institute (2006). A Guide to the Body of Knowledge, Third Edition, PMI, Pennsylvania, USA, str.186.

Stamatović, M., Maksimović, S. \& Tornjanski, A. (2016). Poređenje efikasnosti javnog i privatnog sektora - da li su birokratske procedure izvor neefikasnosti?. Ekonomika, Niš, str.8.

The Green Book (2003). The Green Book: appraisal and evaluation in central government. London: Guidance. str.73-78.

The Security Risk Analysis Directory (n.d.). Introduction to Risk Analysis. The Security Risk Analysis Directory, preuzeto sa: www.security-risk-analysis.com/introduction.htm

Vujnović, M. (2008). Vremenska dimenzija u analizi i proceni projekta, Finansije, str. 6-8.

Wideman, R.M. (1999). Project and Risk Management - Project Risk and Opportunities, PMA, USA, str. 34-37.

Datum prve prijave:

26.02.2020.

Datum prijema korigovanog rada

04.03 .2019

Datum prihvatanja članka:

07.04.2020.

Kako citirati ovaj rad? / How to cite this article?

Style - APA Sixth Edition:

Maksimović, S., Lunjić, A., \& Stamatović, M. (2020, 04 15). Analiza rizika i primena metoda višekriterijumskog odlučivanja u procesima upravljanja projektima. (Z. Čekerevac, Ed.) FBIM Transactions, 8(1), 111-118. doi:10.12709/fbim.08.08.01.11

Style - Chicago Sixteenth Edition:

Maksimović, Snežana, Arben Lunjić, and Milan Stamatović. 2020. "Analiza rizika i primena metoda višekriterijumskog odlučivanja u procesima upravljanja projektima." Edited by Zoran Čekerevac. FBIM Transactions (MESTE) 8 (1): 111-118. doi:10.12709/fbim.08.08.01.11.

Style - GOST Name Sort:

Maksimović Snežana, Lunjić Arben and Stamatović Milan Analiza rizika i primena metoda višekriterijumskog odlučivanja u procesima upravljanja projektima [Journal] // FBIM Transactions / ed. Čekerevac Zoran. - Beograd : MESTE, 04 15, 2020. - 1 : Vol. 8. - pp. 111-118.

Style - Harvard Anglia:

Maksimović, S., Lunjić, A. \& Stamatović, M., 2020. Analiza rizika i primena metoda višekriterijumskog odlučivanja u procesima upravljanja projektima. FBIM Transactions, 15 04, 8(1), pp. 111-118.

Style - ISO 690 Numerical Reference:

Analiza rizika i primena metoda višekriterijumskog odlučivanja u procesima upravljanja projektima. Maksimović, Snežana, Lunjić, Arben and Stamatović, Milan. [ed.] Zoran Čekerevac. 1, Beograd : MESTE, 04 15, 2020, FBIM Transactions, Vol. 8, pp. 111-118 